\title{
ELABORATION OF ORGANIZATIONAL ARRANGEMENTS ON THE IMPROVEMENT OF FUNCTIONING OF THE SYSTEM OF PHARMACEUTICAL SUPPORT OF SUDAN POPULATION
}

\author{
Olena Ievtushenko \\ Department of Pharmaceutical Marketing and Management \\ National University of Pharmacy \\ 53 Pushkinskaya str., Kharkiv, Ukraine, 61002 \\ evtyshenkolena1@gmail.com \\ Abuzaid Osama Mohamed Nour Ahmed \\ Department of Pharmaceutical Marketing and Management \\ National University of Pharmacy \\ 53 Pushkinskaya str., Kharkiv, Ukraine, 61002 \\ abuwaadnour@yahoo.com
}

\begin{abstract}
In the article is considered the problem of support of Sudan population with available pharmaceutical production. The aim of research is an analysis of the price and assortment policy realized by the different pharmaceutical structures, determination of the level of their functions on guaranteeing the availability of medicaments, elaboration on the base of received results the arrangements on optimization of the pharmaceutical support system. It was determined that not all subjects of Sudan pharmaceutical market responsible for the pharmaceutical support cope with such problems at the proper level. Thus in the private drugstores, in the net drugstores of the Ministry of defense «Alia» and in drugstores of the health insurance system the prices of medicament exceed the recommended ones in more than 2 times, an assortment also does not corresponds to both internal and international requirements. The received results indicate the unreasonable use of budget means by the separate state structures, the negative tendencies in the system of guaranteeing the availability of pharmaceutical help.

It was established that the biggest suppliers of the medicaments in Sudan, excluding the state Centre of medicament support CMS cannot ensure the system of health protection with medicaments of the proper quality, assortment and the price rate.

There were elaborated the organizational-economic approaches to optimization of the structure of medical support of Sudan that include the change of the flows of medicaments distribution. There was offered the structure that unites all inflows in the aforesaid CMS and then distributes resources according to the needs of organizations and regions.

Introduction of the offered structures will allow improve the system of purchase and distribution of medicaments, make it transparent. The result of change will be the rise of physical and economic availability of medicaments, widening of assortment, decrease of the price of preparations, significant economy of budget resources.
\end{abstract}

Keywords: pharmaceutical support system, medicaments, assortment price, Africa countries, Sudan.

\section{Introduction}

For today pharmaceutical sector in Sudan suffers from the numerous problems [1-3], which solving is interfered by the lack of financial, material and human resources. Sudan pharmaceutical enterprises produce mainly generic medicaments. The state support of the native producers has mainly declarative character, is not confirmed with legislative acts that results in fact that enterprises lose the competitive fight with the foreign pharmaceutical companies [4-6]. This situation needs for elaboration of the rational approaches to the change of existing system of pharmaceutical help.

The main representatives of the state system of medicament support are the following structures: Centre of medical support (CMS); State revolving drugs fund (RDF); pharmaceutical subdivision Elamal within the service of security and protection; pharmaceutical subdivision Alia 
within the Sudan Ministry of defense. They all are financed from the state budget and was created or authorized for guaranteeing the proper level of availability of pharmaceutical help. But over time it became obvious that the aforesaid structures not equally succeed in their duties. The medicament support system is also formed with the drugstores of private sector, medical insurance systems and donor organization (charity funds and so on).

According to the data from the certain sources, more than $46 \%$ of population in Sudan is beyond the poverty line [1], the level of morbidity and mortality is high [3]. The country has an urgent need for qualified medical specialists [3], equipment [7], medicaments [8,9]. The most part of population pays for the services of the state and private institutions from the own pocket. The share of households with catastrophic outcomes for health protection increased up to $70 \%$ last years [10]. This situation raises the vulnerability of the wider population in the aspect of availability of the medical and pharmaceutical help.

Since 2000 Sudan government accepted several legislative acts, the main one is National medicament policy of Sudan [11, 12], that regulates the circulation and, especially, prices for medicaments in both state and private sectors. According to the discussions about prices for the medicaments and their availability in the Eastern Mediterranean region carried out by the World health protection organization (WHO) $[13,14]$ and Regional bureau of the Eastern Mediterranean countries $[15,16]$, prices for medicaments in Sudan are the one of the highest in the region.

The separate theoretical and practical questions as to the factors that influence an activity of health protective institutions in African and other countries are considered all over the world. Thus M. Khalid in his work [17] carried out an analysis of the price discrepancies and determined the factors of environment and the degree of their influence on the rational use of medicaments. K. M. Gamal [18] outlined the prospects of the native importers at introduction of the more severe rules for guaranteeing the proper quality of medicaments. Salah Ibrahim Kheder [19] in his works also analyzes the price policy of the different subjects of pharmaceutical market, presence and availability of medicaments and the price components. The questions of regulation of pharmaceutical sphere in African countries are elucidated in the annual reports of the World health protection organization [6, 20, 21], Centre of strategic and international studies (USA) [22] and other literature sources $[23,24]$, founded in the UN program "the millennium aims in development" [25]. But for today we can observe the deficiency of the properly structured data on the assortment and prices for medicaments and also the limited number of elaborations as to analysis of existing structure of supply and its optimization.

\section{Aim of research}

Analysis of the price and assortment policy realized by the different pharmaceutical structures, determination of the level of their functioning on guaranteeing the availability of medicaments, elaboration of the arrangements as to optimization of the pharmaceutical help system on the base of the received results.

\section{Materials and methods}

The tasks of research were in determination and analysis of the present assortment and prices for the selected groups of medicaments and in understanding of the dependence of prices on the levels of medicament support system. As the reference point for comparison was taken WHO Model List of Essential Medicines - EML.

The research was carried out during 2015 in Sudan. In the work was used the statistical, comparative and quantitative market analysis of pharmaceutical market. In particular, were studied an assortment and prices for medicaments supplied by the leading pharmaceutical organizations of Sudan. The part of these organizations has the budget financing. With the help of results of the market studies, results of content-analysis $[26,27]$ and on the base of structural analysis was offered the optimized organizational structure of the management of Sudan pharmaceutical sector that presupposes the changes just in the section of pharmaceutical support (supply and distribution system). 


\section{Results of research}

The first stage of research was an analysis of the medicaments assortment in the main subjects of pharmaceutical market, especially: drugstores of the Centre of medical supply CMS, drugstores of the private sector, medical insurance system and also the system of medicament support of the armed forced of the country (drugstore net «Alia»). It is worth noting, that the Centre of medical support and system of medicament support of the Sudan armed forces have the budget financing. The other structures were not considered because of insignificant circulation of medicaments. The received results presented in Table $\mathbf{1}$.

\section{Table 1}

Correspondence of medicaments assortment in the objects of Sudan pharmaceutical support to the criteria recommended by WHO

\section{Medicaments assortment in correspondence with the recommended list «WHO essential medicine list»}

Medicaments assortment in the drugstore nets of the country

\section{CMS Private sector}

\author{
Medical insurance \\ system
}
Armed forces system (departmental drugstore net «Alia»)

\begin{tabular}{|c|c|c|c|c|c|c|c|c|c|}
\hline number & share, $\%$ & number & $\begin{array}{l}\text { Share relative } \\
\text { to the recom- } \\
\text { mended list, \% }\end{array}$ & number & $\begin{array}{l}\text { Share relative } \\
\text { to the recom- } \\
\text { mended list, \% }\end{array}$ & number & $\begin{array}{l}\text { Share relative } \\
\text { to the recom- } \\
\text { mended list, \% }\end{array}$ & number & $\begin{array}{l}\text { Share relative } \\
\text { to the recom- } \\
\text { mended list, \% }\end{array}$ \\
\hline 399 & 100 & 237 & 59.40 & 198 & 49.62 & 97 & 24.31 & 71 & 18.00 \\
\hline
\end{tabular}

The next stage of research was an analysis of the price policy in aforesaid organizations during the year. The collection of data was carried out 4 times a year (1 time a quarter); the mean arithmetic indices took part in the research. The results of research are presented in the Table 2.

The basic index in this case were prices in CMS drugstores compared with prices for analogous goods in other system organizations.

Table 2

Mean basic indices of growth/decrease of prices in the leading organizations of Sudan medicament support system

Mean basic indices of growth/decrease of retail prices in the different structural subdivisions of Sudan medicament support system, $\mathrm{k}_{\mathrm{b}}$

CMS drugstores

Net drugstores of the Ministry of defense «Alia»

1,87
Medical insurance drugstores

1,89
Private drugstores
1

(1)

On the base of the research and analysis of scientific publications [20, 23, 24, 26, 27] was offered the optimized structural scheme of the medicament support in Sudan (Fig. 1, 2). 


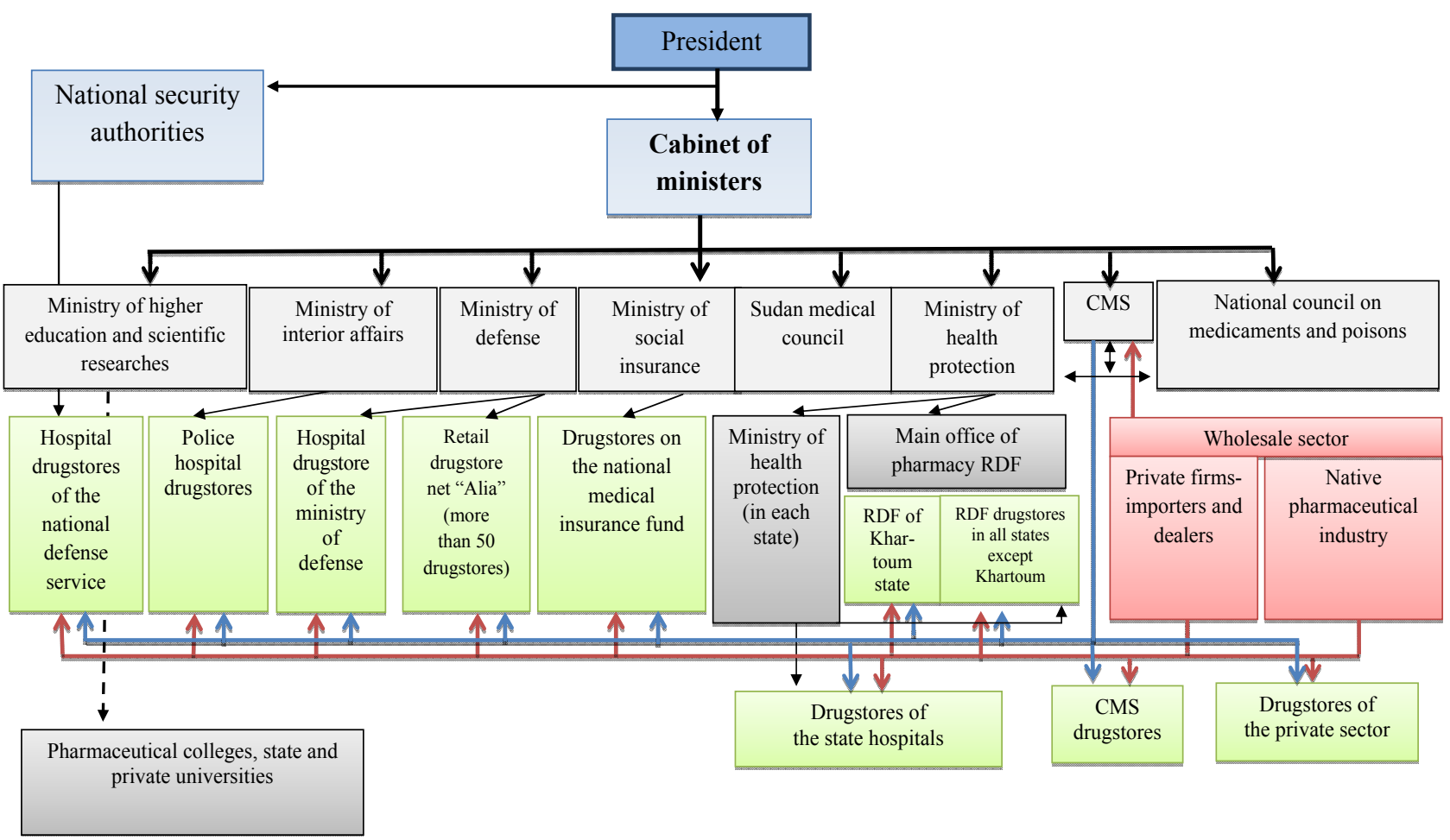

Fig. 1. Existing organizational structure of the management of Sudan pharmaceutical sector

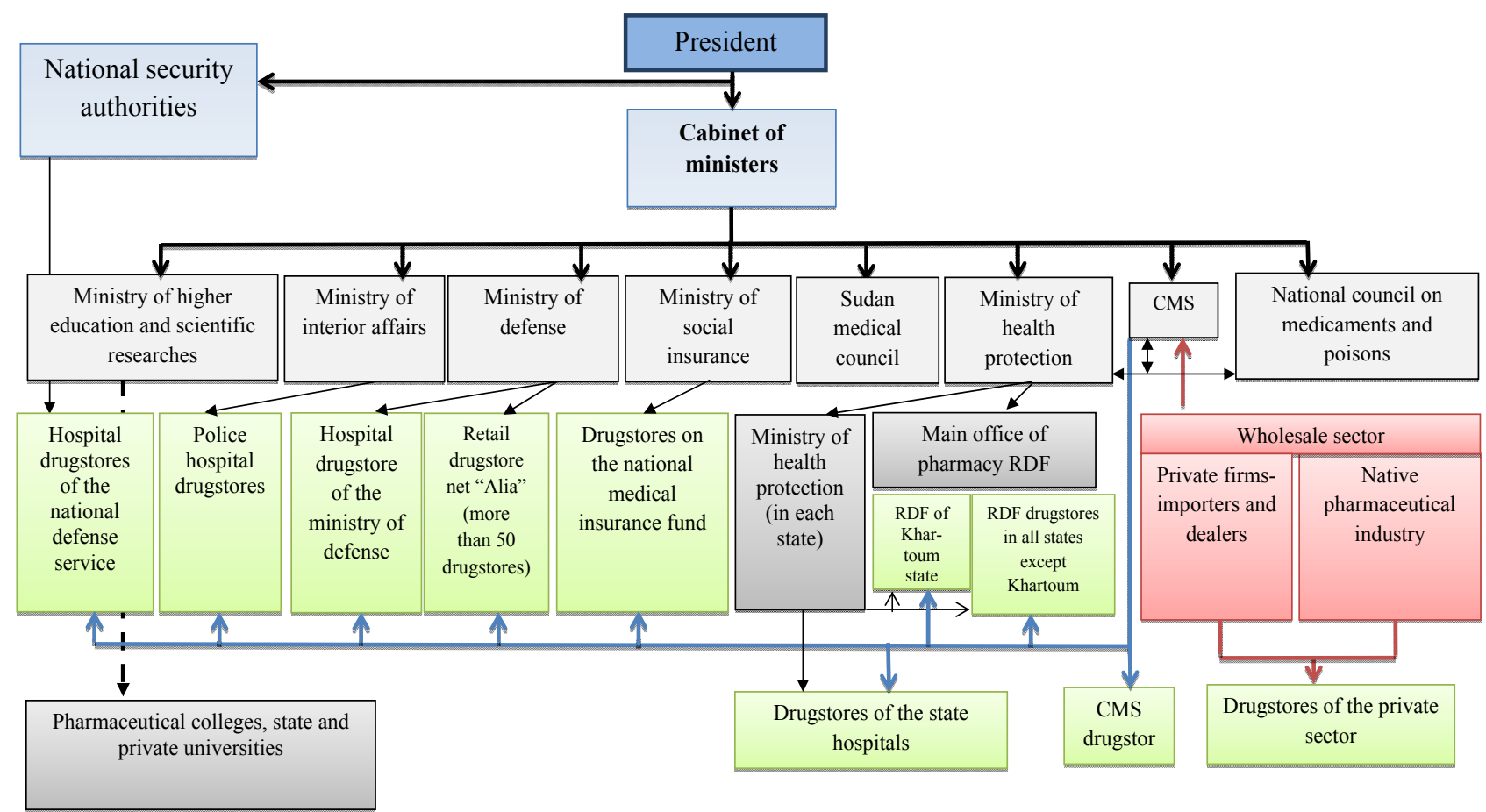

Fig. 2. Offered organizational structure of the management of Sudan pharmaceutical sector

\section{Discussion of the results of research}

Comparing the assortments of aforesaid organizations with the model list of the main medicaments recommended by WHO (it includes 399 names) we can note the following. 
The drugstores of CMS system provide 59,40\% of the assortment recommended by WHO, drugstores of the private sector $-49,62 \%$, drugstores of the medical insurance $-24,31 \%$, and the drugstore net of the armed forces system of the country "Alia" provide 18,00\% of the recommended points. So, the state system of distribution provides near $60 \%$ of the necessary assortment, private sector also provides the rather wide spectrum of medicaments near $50 \%$, and the medical insurance and the armed forces systems of the country practically cannot cope with the problem. It was established, that the system of state support CMS in addition to the main list has the lists of medicaments that are present also in the lists of such organizations as UNICEF and UNDPE (UN programs of development). CMS deals with receipt of medicaments from the donor organizations, storage and distribution free of charge within the programs accepted at the state level. Most of these preparations are aimed at the treatment of the socially significant diseases such as malaria, tuberculosis, AIDS (near 340 names).

At analysis of the price policy realized by these subjects of pharmaceutical market of Sudan was determined that the highest prices were registered in the private drugstores - it exceeds the ones of CMS drugstores more than by $100 \%$ in average. The unreasonably high prices are in the net drugstores of the Sudan Ministry of defense "Alia" and in ones of the medical insurance system - their indices indicate the unsatisfactory organizational measures on guaranteeing the availability of medicaments - excess is near $90 \%$.

Thus all organizations except CMS cannot be the main structures that supply the health protection system with medicaments of proper quality, assortment and price indices. This question is especially urgent at consideration of the support system of the Ministry of defense that functions due to the budget means and, consequently, uses its rather small resources irrationally.

In the further the development of the following directions of this research is possible separate analysis of the presence and prices of original and generic preparations, monitoring of prices at the different levels of goods circulation (wholesale and retail link) and also the comparative analysis of the aforesaid indices in the different geographic zones of Sudan. So, the analysis of the cheap generics will allow determine the level of economic availability of medicaments in the country and analysis of the presence and availability of original preparations will allow make conclusions about how spread are the last achievements of pharmaceutical science and how difficult to get an access to them.

Unfortunately, the Sudan state system of medicament support is characterized with decentralized management of purchases and supplies of medicaments. Many state structures (army, police and so on) often make the direct purchases at the private enterprises, pharmaceutical factories, in dealers of the foreign companies. Such decentralization when the state wholesale pharmaceutical organization - Centre of medical support CMS - does not participate in this process is economically unprofitable for the state. It favors the conditions for misuses and conflict situations. The assortment of these organizations does not correspond to the minimal requirements, the retail prices are overestimated in few times (that testifies to the permanent violation of the law or organization of illegal schemes in the drugstore work) that result in the decrease of availability of pharmaceutical help in the country where the infectious and other disease are widespread and the lion's share of population is beyond the poverty line.

We carried out analysis of the structure and activity of the state system of the Revolving Drug Fund (RDF), Center of medical support (CMS) and system of support of the Sudan Ministry of defense. The literature sources [23-27] indicate the problems at the simultaneous functioning of RDF and CMS. The main one - at purchases of medicaments and their distribution RDF often acts as a parallel structure that duplicates the functions of CMS. Analysis of assortment and price policy showed that the system of support of the Ministry of defense also does not cope with the set problems: prices for preparations are overestimated (corruption component), assortment does not correspond to the minimal requirements, complications with 
an access to the pharmaceutical storages and drugstores (the access of pharmaceutical inspection is limited), the function of the main state supplier are duplicated.

The research showed that it is expedient to choose the centralization of the medicament support system as the priority direction of the improvement of structure of Sudan state sector of pharmaceutical market.

At introduction of the new model of medicament support system the following results are expected:

- economy of budget means, decrease of the number of misuses;

- formation of the unite approach to the guaranteeing of the proper quality of medicament, distribution, transporting, warehousing and storage (at the expense of compliance with GSP, GDP requirements);

- elimination of duplicated functions by the main organizations-suppliers of medicaments;

- introduction of the unite system of reporting (rise of the distinctness of the received data, clearness in the work of purchases distribution and prognostication systems);

- economy of accommodations for the medicaments storage, reduction of the transport outcomes, diminishing of the number of staff for the system maintenance;

- unite approach to the selection and teaching of the workers (qualified and motivated staff);

- rise of effectiveness of solving questions of the rational use of medicaments and pharmaceutical surveillance;

- decrease of the number of falsified and bad pharmaceutical production in circulation;

- reorganization of the work on purposeful programs on the fight against malaria, HIV $\backslash$ AIDC (rise of the effectiveness of these working directions).

Thus, there were offered the organizational-economic approaches to optimization of the structure of Sudan medicament support that will raise the effectiveness of the existing systems of purchase and distribution of medicaments, have a positive effect on physical and economic availability of pharmaceutical help.

\section{Conclusions}

1. There was carried out an analysis and monitoring of the price policy in the different subjects of the Sudan medicament support system that demonstrated the following:

- the highest prices were fixed in the private drugstores - the mean basic indices of the growthldecrease of retail prices relative to the ones of Centre of medicament support (CMS) - 2,1;

- the indices of the net drugstores of Sudan Ministry of defense "Alia" and the ones of the medical insurance system indicate the unsatisfactory organizational arrangements on guaranteeing the medicaments availability -the mean basic indices of growth/decrease of prices are 1,87 and 1,89 respectively.

The results indicate the irrational use of budget means by the separate state structures, the negative results of the work on guaranteeing the pharmaceutical help availability.

2. There were elaborated organizational-economic approaches to optimization of Sudan medicament support structure that include the change of flows of medicament distribution. There was offered the structure that unifies all inflows in the state company CMS (Sudan Centre of medicament support) and then distributes the resources according to the needs of organizations and regions.

3. Introduction of the offered arrangements will allow essentially improve the existing systems of medicaments purchase and distribution, control these processes, make them transparent.

There was offered the rise of physical and economic availability of pharmaceutical help by the way of widening of assortment, lowering of the price for medicaments almost in 2 times, strengthening of the control on the quality and safety of the used preparations.

At macro level the morbidity and mortality rates will be lowered, the health status and life quality of nation will improved, the significant economy of both state and own patient's savings will be attained. 


\section{References}

[1] Roshhin, G. E. (2013). Mezhdunarodnye korporacii v Afrike. Azija i Afrika segodnja, 12, 30-33.

[2] Sudan: ser'eznye problemy s medicinoj. Available at: http://peopleandcountries.com/article-784-1.html

[3] Eastern Mediterranean Region. Framework for health information systems and core indicators for monitoring health situation and health system performance (2015). WHO. Available at: http:// applications.emro.who.int/dsaf/EMROPUB_2015_EN_1904.pdf?ua=1\&ua=1

[4] Annual Statistical Report 2014. Annual Health Statistics Reports 2014. Federal Ministry of Health (Sudan). National Center for Health Information. Available at: http://www.sho.gov.sd/controller/ kn_hub_\%20featured.php?sm_id=133\&mid=110\&lid=1\#

[5] Sudan. Oficial'nye sajty. Available at: http://polpred.com/?cnt=148\&cat=5

[6] Sudan: statisticheskie dannye. WHO. Available at: http://www.who.int/countries/sdn/ru/

[7] Organizacija zdravoohranenija v razvivajushhihsja stranah. Available at: http://helpiks.org/234536.html

[8] FIP global Pharmacy: Workforce Report (2012). Available at: https://www.fip.org/static/fipeducation/2012/FIP-Workforce-Report-2012/?page=hr2012\#/54

[9] Bate, R., Jin, G. Z., Mathur, A. (2011). Does price reveal poor-quality drugs? Evidence from 17 countries. Journal of Health Economics, 30 (6), 1150-1163. doi: 10.1016/j.jhealeco.2011.08.006

[10] Niens, L., Van de Poel, E., Cameron, A., Ewen, M., Laing, R., Brouwer, W. (2012). Practical measurement of affordability: an application to medicines. Bulletin of the World Health Organization, 90 (3), 219-227. doi: 10.2471/blt.10.084087

[11] Health System Financing Review Report (2014). Sudan Federal Ministry of Health. Available at: http://docplayer.net/3744434-Health-system-financing-review-report-may-2014-sudan-federal-ministryof-health.html

[12] NMP 2005. National Medicine Policy (2005). Khartoum (Sudan): Federal Ministry of Health, 311.

[13] Gamal, K. M. A., Abdeen, M. O. (2012). Pharmaceuticals in Sudan: Development in regulations, governance and implementation of national drug policies. African Journal of Pharmacy and Pharmacology, 6 (1), 1-12. doi: 10.5897/ajpp11.023

[14] Global pharmacy. Workforce report (2012). Federation Internationale Pharmaceutique (FIP). Hague. FIP publishing, 85.

[15] Creese, A. (2011). Sales Taxes on Medicines. WHO/HAI Project on Medicine Prices and Availability. Pharmaceutical Pricing Policies and Interventions, 49. Available at: http://docplayer. net/228639-Who-hai-project-on-medicine-prices-and-availability-review-series-on-pharmaceutical-pricing-policies-and-interventions.html

[16] Medicine Prices, Availability and Affordability in Sudan. Report of a survey conducted in February - March 2013 (2013). Available at: http://www.haiweb.org/medicineprices/surveys/201302SD/ sdocs/Sudan_survey_report_2013.pdf

[17] Ali, H., Mahmoud, R. (2013). Analysis of price discrepancies and its impact on rational use of medicines. Sudan Medical Monitor, 8 (4), 189. doi: 10.4103/1858-5000.133021

[18] Gamal, K. M. (2007). The impact of the pharmaceutical regulations on the quality of medicines On the Sudanese market: Importers' perspective. Sudanese Journal of Public Health, 2 (3), 157-167.

[19] Kheder, S., Ali, H. (2014). Evaluating medicines prices, availability, affordability and price components in Sudan. Sudan Medical Monitor, 9 (1), 19. doi: 10.4103/1858-5000.144655

[20] WHO/HAI Project on Medicine Prices and Availability (2011). Pharmaceutical Pricing Policies and Interventions. Available at: http://haiweb.org/wp-content/uploads/2015/08/ERP-final-May 2011a1.pdf

[21] The African Regional Health Report. WHO. Available at: http://www.who.int/mediacentre/ news/releases/2006/pr68/ru/

[22] Database of The American Society of Health-System Pharmacists resources (ASHP) (2012). Available at: http://www.ashp.org 
[23] Gamal, K. M. A., Abdeen, M. O. (2011). Privatisation of the Central Medical Supplies (CMS) public corporation: Why not? Research In Pharmaceutical Biotechnology, 3 (8), 104-110.

[24] Gamal, K. M. A. (2010). Can the Public Central Medical Supplies Corporation of Sudan balance a policy for delivering low-cost medicines whilst maintaining quality? Sudanese Journal of Public Health, 5 (3), 115-121.

[25] Millennium Development Goals (MDGs). WHO. Available at: http://www.who.int/topics/millennium_development_goals/about/ru/

[26] NMSF Supply Chain Model: States' Medical Supply Fund (2013). Khartum: FMOH-NMSF, 29. Available at: http://www.nmsf.gov.sd/includes/pdf/supply_model.pdf

[27] Mahgoub, M. H., Mohamed I. B. M. I. (2009). Do systems contribute to the sustainability of the Revolving Drug Fund (RDF) in Sudan? Sudanese Journal of Public Health, 4 (2), 288-295. 